\title{
Large-scale malaria survey in Cambodia: Novel insights on species distribution and risk factors Sandra Incardona ${ }^{1}$, Sirenda Vong ${ }^{2}$, Lim Chiv ${ }^{3}$, Pharath Lim¹, Sina Nhem ${ }^{3}$, Rithy Sem ${ }^{3}$, Nimol Khim ${ }^{1}$, Socheat Doung, ${ }^{3}$, Odile Mercereau-Puijalon ${ }^{4}$ and Thierry Fandeur*1,4
}

\begin{abstract}
Address: ${ }^{1}$ Laboratory of Molecular Epidemiology, Institut Pasteur du Cambodge, Phnom Penh, Cambodia, ${ }^{2}$ Epidemiology and Public Health Unit, Institut Pasteur du Cambodge, Phnom Penh, Cambodia, ${ }^{3}$ National Centre for Parasitology, Entomology and Malaria Control, Phnom Penh, Cambodia and ${ }^{4}$ Unité d'Immunologie Moléculaire des Parasites, Institut Pasteur, 28 rue du Dr Roux, 75724 PARIS cedex 15, France

Email: Sandra Incardona - sandra.incardona@yahoo.fr; Sirenda Vong - svong@pasteur-kh.org; Lim Chiv - cnm@bigpond.com.kh; Pharath Lim - pharath@pasteur-kh.org; Sina Nhem - nsina@pasteur-kh.org; Rithy Sem - srithy@pasteur-kh.org; Nimol Khim - knimol@pasteurkh.org; Socheat Doung - socheatd@cnm.gov.kh; Odile Mercereau-Puijalon - omp@pasteur.fr; Thierry Fandeur* - tfandeur@pasteur.fr

* Corresponding author
\end{abstract}

Published: 27 March 2007

Malaria Journal 2007, 6:37 doi:10.1186/1475-2875-6-37

This article is available from: http://www.malariajournal.com/content/6/1/37

(c) 2007 Incardona et al; licensee BioMed Central Ltd.

This is an Open Access article distributed under the terms of the Creative Commons Attribution License (http://creativecommons.org/licenses/by/2.0), which permits unrestricted use, distribution, and reproduction in any medium, provided the original work is properly cited.

\begin{abstract}
Background: In Cambodia, estimates of the malaria burden rely on a public health information system that does not record cases occurring among remote populations, neither malaria cases treated in the private sector nor asymptomatic carriers. A global estimate of the current malaria situation and associated risk factors is, therefore, still lacking.

Methods: A large cross-sectional survey was carried out in three areas of multidrug resistant malaria in Cambodia, enrolling 1I,652 individuals. Fever and splenomegaly were recorded. Malaria prevalence, parasite densities and spatial distribution of infection were determined to identify parasitological profiles and the associated risk factors useful for improving malaria control programmes in the country.

Results: Malaria prevalence was 3.0\%, 7.0\% and I2.3\% in Sampovloun, Koh Kong and Preah Vihear areas. Prevalences and Plasmodium species were heterogeneously distributed, with higher Plasmodium vivax rates in areas of low transmission. Malaria-attributable fevers accounted only for 10-33\% of malaria cases, and $23-33 \%$ of parasite carriers were febrile. Multivariate multilevel regression analysis identified adults and males, mostly involved in forest activities, as high risk groups in Sampovloun, with additional risks for children in forest-fringe villages in the other areas along with an increased risk with distance from health facilities.

Conclusion: These observations point to a more complex malaria situation than suspected from official reports. A large asymptomatic reservoir was observed. The rates of $P$. vivax infections were higher than recorded in several areas. In remote areas, malaria prevalence was high. This indicates that additional health facilities should be implemented in areas at higher risk, such as remote rural and forested parts of the country, which are not adequately served by health services. Precise malaria risk mapping all over the country is needed to assess the extensive geographical heterogeneity of malaria endemicity and risk populations, so that current malaria control measures can be reinforced accordingly.
\end{abstract}




\section{Background}

Cambodia has long been a region of endemic malaria. After much inconsistencies and political turmoil, the country has now established an efficient malaria control programme and has recently been cited as one of the countries most efficiently fighting against malaria [1]. Between 1997 and 2005, the number of malaria cases decreased by $57 \%$, thanks to the complementary control strategies implemented during the last decade by the National Centre for Parasitology, Entomology and Malaria Control (previously 'Centre National de Malariologie' CNM) [2-5]. Nevertheless, rates of mortality and morbidity are still at unacceptable levels in some areas, justifying continued efforts to combat the disease [6]. About 74,185 malaria cases were reported by CNM in 2005, of which 49,436 were confirmed by laboratory diagnosis The clinically most relevant species, Plasmodium falciparum, accounted for $80 \%$ of infections [3].

Current estimates of the malaria burden in Cambodia rely on the data collected by the public health information system (HIS) that does not record malaria cases occurring among remote populations. These data include symptomatic patients consulting in public sector health facilities $[2-4,7]$, whereas malaria cases treated by traditional healers or private practitioners remain unrecorded. Although clinical malaria incidence has decreased, the extent and distribution of asymptomatic carriage that significantly contributes to transmission is, therefore, missed by the present information system. Furthermore, only a few studies on malaria prevalence and parasite species distribution have been published so far in Cambodia. These were limited to ethnic comparisons, entomological studies, surveys of refugees or migrant workers, and thus their relevance for the actual prevailing malaria situation is unclear [8-11]. Two independent studies have shown that the private health sector plays a large role in malaria case management, especially in remote areas, with only $18-$ $19 \%$ of individuals seeking their first treatment at the nearest public health facility $[12,13]$. The global malaria situation and associated risk factors are still under-documented in Cambodia.

To gain a better insight into the malaria situation at the province level, malaria parasitologic profiles and spatial distribution of infections in populations living along the Thai border, in three areas of multidrug resistant malaria were determined $[5,14,15]$. Detailed parasitologic data were used to derive baseline information for planning and updating malaria control programmes in these areas.

\section{Study subjects and methods Study areas}

The national HIS indicates a high malaria incidence in the border provinces of Cambodia (Figure 1) where the major malaria vectors Anopheles dirus, Anopheles minimus and Anopheles maculatus are widespread in forest-covered hills and mountains $[5,7,16,17]$. The study focused on three regions bordering Thailand: the Preah Vihear province in the North; the Sampovloun operational district (Battambang province) in the North-west; and the Koh Kong province in the South-west. In 2002, the recorded annual parasite incidence per 1,000 inhabitants (API) in Sampovloun, Koh Kong and Preah Vihear was of 36.4, 5.5 and 39.2 , respectively, whereas the national average was of 3.6 (Dr Tol Bunkea, CNM, unpublished results) [3]. These provinces are located in an area of $P$. falciparum multidrug resistance $[5,14,15]$. No data were available for Koh Kong itself, but high levels of in vivo and in vitro drug resistance were reported in neighbouring provinces of Pursat and Kompong Speu, which border Koh Kong in the North and the East, respectively.

Malaria transmission occurs mostly during the rainy season, with substantial regional and year-to-year variations. The survey periods, namely : November/December 2001 in Sampovloun, March 2002 in Koh Kong and August/ September 2003 in Preah Vihear, were chosen according to previous CNM records (Dr Tol Bunkea, CNM, unpublished results) [3] in order to coincide with the respective transmission seasons.

\section{Study design and subjects}

The sample size to be screened was calculated to yield a 95 $\% \mathrm{CI}$ and a precision level of $1 \%$ using Sampsize software [18]. Based on the total population size in these provinces, estimated to be 225095 from the last census, and after excluding urban centers and places where no malaria transmission occurs, a sample size of 9211 persons was calculated. Villages were randomly selected from the 1998 nationwide census village list. Some logistically inaccessible villages were replaced by the closest accessible village. In Sampovloun, some villages were divided between the villages themselves and the so-called "chamkar" (farms), which were considered as one village entity. In numerous places the composition and location of households was highly heterogeneously distributed precluding an appropriate randomization of households which furthermore would not have yielded the aimed sample size. A global sampling method aiming at coverage of all inhabitants was used. Village chiefs were informed about the purpose and date of the visit to ensure maximum participation of the villagers. All villagers present on the scheduled day of the survey were enrolled under the supervision of the village Chiefs and malaria control agents from the Ministry of Health. For each participant, informed consent was obtained, an identification code was issued, and age, gender, bednet use were recorded. The occupation of the individuals was recorded and classified in three categories: 'inside village' ('child', 'school', 'staying at home'), 'out- 


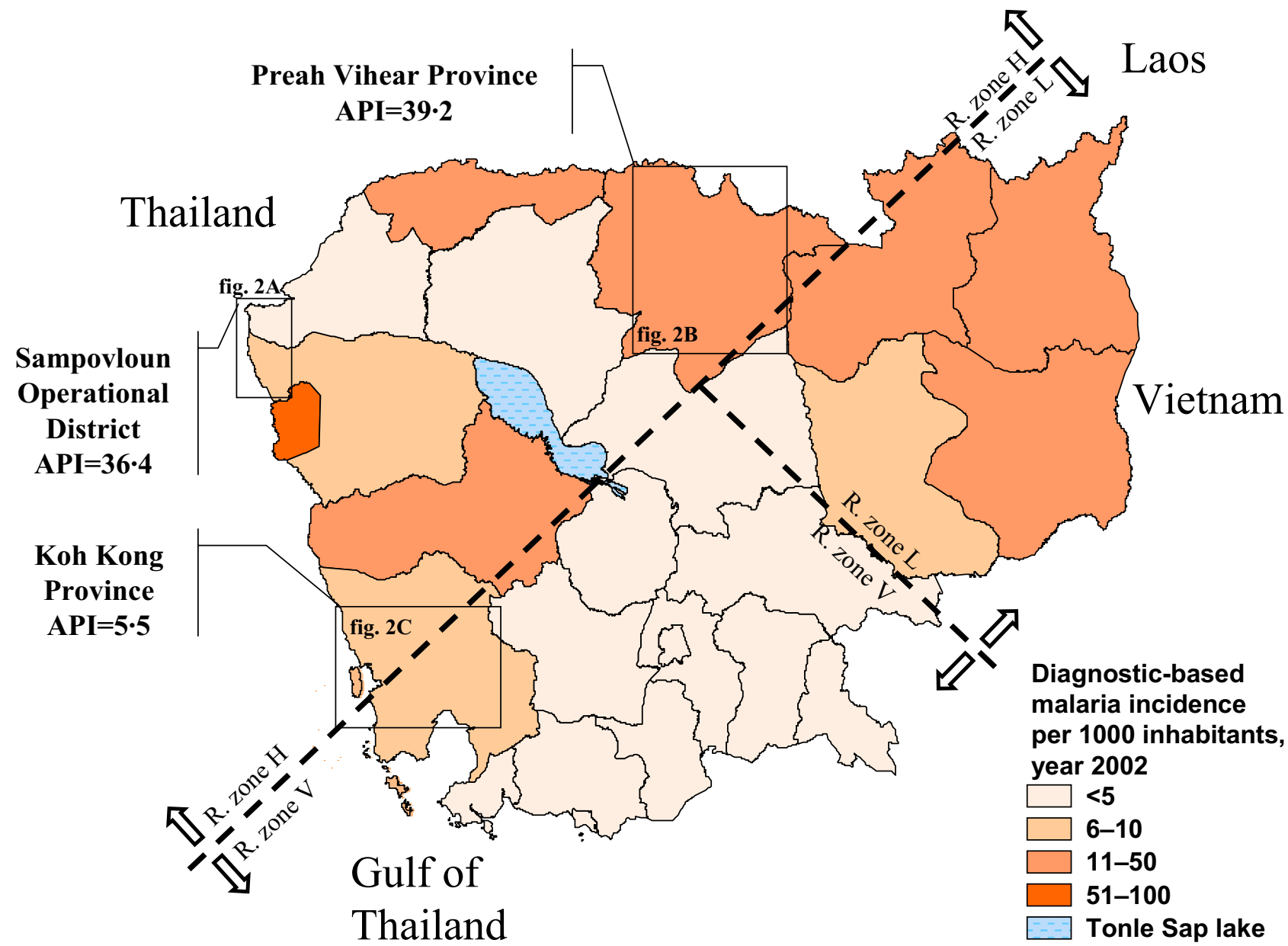

Figure I

Reported malaria cases and $\boldsymbol{P}$. falciparum drug-resistance areas in Cambodia, year 2002. The annual parasite incidence (API) per I,000 inhabitants, confirmed by blood-slide examination or rapid diagnosis test, is shown for each province of Cambodia (source: National Malaria Center, 2002). The country is also divided in areas of low (L), variable (V) and high (H) resistance of $P$. falciparum to chloroquine. The three surveyed regions and their respective annual parasite incidences in 2002 are indicated (detailed maps in Figure 2).

side village' ('farmer', 'military'), and 'other' ('fisher', 'vendor', 'NGO agent', 'unknown'). The axillary temperature was measured and splenomegaly was determined using the Hackett classification (grade 1-5). For individuals with fever or other malaria-related symptoms, a rapid diagnosis test was carried out (Paracheck Pf, Orchid, India or OptiMAL-IT, Diamed, Switzerland). Individuals testing positive were treated according to national guidelines (artesunate + mefloquine for Plasmodium falciparum infections, chloroquine for Plasmodium vivax infections). Fingerprick blood was collected from all individuals for both thin and thick smears. The study was approved by the Cambodian National Ethics Committee.

\section{Microscopy and case definitions}

Thin smears were fixed with methanol, and slides were stained with 3\% Giemsa for $30 \mathrm{~min}$. The slides were examined by experienced microscopists at the CNM. At least
100 thick film fields at $1,000 \times$ magnification were examined before a slide was considered negative. Parasite species and stages were confirmed on the thin film. Densities were scored as follows: $1+$ for 1-10 parasites per 100 thick film fields; $2+$ for 11-100 parasites per 100 fields; $3+$ for 1-10 parasites per single field; $4+$ for 11-100 parasites per single field; $5+$ for $>100$ parasites per single field (WHO, Basic Malaria Microscopy, Geneva, Switzerland)

Malaria infection was defined as the presence of Plasmodium parasites on microscopy slides. Malaria-attributable fever cases and symptomatic malaria cases were defined as individuals with fever and a positive microscopy result, irrespective of the parasite density [19].

Splenomegaly was either positive (Hackett grade $2-5$ ) or negative (Hackett grade 1). Fever was defined as an axillary temperature $\geq 37.5^{\circ} \mathrm{C}$. 


\section{Geographical positioning and analysis}

The coordinates of the survey villages were taken from the 1998 census database (National Institute of Statistics, Cambodian Ministry of Planning). The villages not listed in the database were recorded on site using a Global Positioning System. The coordinates of the government health facilities were taken from the 2003 Administrative Health Facility Mapping database (National Institute of Statistics). Roads, water and forest data were from the 2003 Cambodia Reconnaissance Survey Digital Data of the Cambodian Ministry of Public Works and Transportation and the Japan International Cooperation Agency (JICA), which derived from various sources (maps, aerial and satellite photographs, field verifications) dating from 19921996 in Koh Kong, and from 1994-2002 in Preah Vihear and Sampovloun.

The ArcGIS v9.0 software (ESRI Systems, Redland, CA, USA) was used to measure the distances between villages and i) the nearest public health care service, and ii) the nearest forest potentially harboring malaria vectors, using Euclidian distance measurements, the category "evergreen broad leafed forest" was considered most likely associated with a high $A$. dirus and $A$. minimus abundance, in agreement with experience and data of the Entomology Department of the CNM (Dr Tho Sochantha, CNM, unpublished results) [3].

\section{Statistical analysis}

An anonymous database was created and double-checked. Stata v8.0 was used for all statistical analyses. Association of the individual's characteristics and the village's distance-to-forest and distance-to-health-facility covariates with malaria prevalence was analyzed by a generalized linear mixed model with a logistic regression function (Stata command 'gllamm', Generalized Linear Latent and Mixed Model). Variables with a $p$ value $<0.05$ in the bivariate analysis were retained in the model. Variables with correlation coefficients $>0.70$, indicating co-linearity, were not included together in the model. Interaction between relevant risk factors was assessed by comparing the models with and without the interaction factor using the log-likelihood ratio test and a significant $p$ value of $<$ 0.05 .

\section{Results}

\section{Study population}

About 11,652 individuals from 88 villages accounting for $2 \%-8 \%$ of the targeted populations in the three areas were tested for malaria (Table 1). Most of the participants were between 5 and 39 years old. The male/female ratio was lower in the adult population aged $\geq 15$ years than in $<15$ year old children ( 0.56 versus 0.97 ). Most individuals had activities within the village, although a large number (39$43 \%$ ) regularly worked outside the village. Bednets were used by most individuals, particularly in Sampovloun and Koh Kong areas (98\% for both).

\section{Malariometric indices}

Data on parasite prevalence, spleen enlargement and fever rates are presented in Table 2. Plasmodium spp. prevalence was $3.0 \%, 7.0 \%$ and $12.3 \%$ in Sampovloun, Koh Kong and Preah Vihear, respectively. P. falciparum was predominant in Preah Vihear and Koh Kong (75\% and 65\% of positive cases, respectively), whereas nearly half of the positive cases in Sampovloun were due to $P$. vivax. Mixed infections, mainly $P$. falciparum and $P$. vivax, were detected in $6-9 \%$ of positive slides. Eight Plasmodium malariae infections were identified during the survey, but Plasmodium ovale was not observed.

P. falciparum gametocyte carriage, ranging from 9 to $15 \%$ of the positive cases, did not differ significantly in the three survey areas. By contrast, $P$. vivax gametocytes were detected at lower rates and solely in Sampovloun and Koh Kong areas (Table 2). In Preah Vihear, P. falciparum gametocytes were more frequent in $<5$ year old children than in older age groups $(17.2 \%$ versus $9.4 \%, p=0.033)$. Similarly, sexual forms were significantly most prevalent in samples with low grade parasite densities (15.4\% versus $5.5 \%, p<0.001)$.

Spleen rates were low among the surveyed population and in 2-9 year old children $(1-2 \%)$, but were higher in parasite-positive individuals, reaching 6-9\%. In Preah Vihear and Koh Kong areas, where malaria transmission is more marked, spleen enlargement was more frequent in children aged $<15$ years than in individuals aged $\geq 15$ years (2.0\% versus $0.3 \%, p<0.001$ and $1.5 \%$ versus $0.4 \%, p=$ 0.003 , respectively) whereas in Sampovloun, it was only observed in individuals aged $\geq 5$ years.

\section{Morbidity and parasite density}

In Preah Vihear, 33\% of fever cases were associated with a Plasmodium spp. infection, versus $10 \%$ and $17 \%$ in Koh Kong and Sampovloun, respectively (Table 2). As a consequence, the positive predictive values of fever as a presumptive diagnosis criterion was very low (PPV of $16.7 \%$, $10.1 \%$ and 33.0\%, in Sampovloun, Koh Kong and Preah Vihear, respectively). Symptomatic malaria infections were observed in approximately one-quarter (Koh Kong) and one-third (Sampovloun, Preah Vihear) of parasitepositive individuals, and were significantly more frequent in men than in women for the three areas $(37.4 \%$ versus $23.0 \%, p<0.001)$. In Preah Vihear, $P$. falciparum parasite density was higher in $<5$ year old children than in the older age groups (densities $>2+$ being observed in $45.1 \%$ versus $28.8 \%$ of infections, $p=0.004)$. In all the three survey areas, fever rates increased with parasite densities, especially between densities $<3+$ and $\geq 3+$ for both $P$. fal- 
Table I: Characteristics of study population and univariate analysis of malaria risk factors

\begin{tabular}{|c|c|c|c|c|c|c|c|c|c|c|c|c|c|c|c|}
\hline & \multicolumn{5}{|c|}{ Sampovloun } & \multicolumn{5}{|c|}{ Koh Kong } & \multicolumn{4}{|c|}{ Preah Vihear } & \\
\hline & \multicolumn{2}{|c|}{ Surveyed } & \multicolumn{3}{|c|}{ P. spp. positive } & \multicolumn{2}{|c|}{ Surveyed } & \multicolumn{3}{|c|}{ P. spp. positive } & \multicolumn{2}{|c|}{ Surveyed } & \multicolumn{3}{|c|}{ P. spp. positive } \\
\hline & No & $\%$ & No & $\%$ & P & No & $\%$ & No & $\%$ & $P$ & No & $\%$ & No & $\%$ & P \\
\hline No of villages & 27 & & & & & 38 & & & & & 23 & & & & \\
\hline No of individuals & 4074 & & 123 & 3.0 & & 2624 & & 184 & 7.0 & & 4954 & & 610 & 12.3 & \\
\hline \multicolumn{16}{|l|}{ Age } \\
\hline$<5$ years & 363 & 8.9 & 4 & I.I & $<0.001$ & 229 & 8.7 & 7 & 3.1 & $<0.001$ & 922 & 18.6 & 112 & 12.2 & 0.002 \\
\hline $5-14$ years & 1586 & 38.9 & 26 & 1.6 & & 915 & 34.9 & 79 & 8.6 & & 1748 & 35.3 & 242 & 13.8 & \\
\hline $15-39$ years & 1434 & 35.2 & 76 & 5.3 & & 966 & 36.8 & 78 & 8.1 & & 1739 & 35.1 & 214 & 12.3 & \\
\hline$\geq 40$ years & 691 & 17.0 & 17 & 2.5 & & 514 & 19.6 & 20 & 3.9 & & 545 & 11.0 & 42 & 7.7 & \\
\hline \multicolumn{16}{|l|}{ Gender } \\
\hline female & 2258 & 55.4 & 43 & 1.9 & $<0.001$ & 1513 & 57.7 & 83 & 5.5 & $<0.001$ & 2938 & 59.3 & 323 & 11.0 & 0.001 \\
\hline male & 1816 & 44.6 & 80 & 4.4 & & 1111 & 42.3 & 101 & 9.1 & & 2016 & 40.7 & 287 & 14.2 & \\
\hline \multicolumn{16}{|l|}{ Occupation* } \\
\hline inside village & 2183 & 53.6 & 35 & 1.6 & $<0.001$ & 1216 & 46.3 & 81 & 6.7 & 0.023 & 2910 & 58.7 & 378 & 13.0 & 0.07 \\
\hline outside village & 1764 & 43.3 & 88 & 5.0 & & 1027 & 39.1 & 95 & 9.3 & & 2015 & 40.7 & 227 & 11.3 & \\
\hline \multicolumn{16}{|l|}{ Bednet use } \\
\hline Yes & 3996 & 98.1 & 117 & 2.9 & 0.015 & 2569 & 97.9 & 180 & 7.0 & 0.939 & 4313 & 87.1 & 496 & 11.5 & $<0.001$ \\
\hline no & 78 & 1.9 & 6 & 7.7 & & 55 & 2.1 & 4 & 7.3 & & 641 & 12.9 & 114 & 17.8 & \\
\hline
\end{tabular}

* unclassified occupations were excluded

The age, gender, occupation and bed-net use distribution is shown for the surveyed population (representing $7.7 \%, 1.9 \%$ and $4.0 \%$ of the population covered by the public health system in Sampovloun, Koh Kong and Preah Vihear, respectively), and for the individuals testing positive for Plasmodium by microscopy. $P$ values from a univariate analysis of malaria prevalence distribution in each area are also shown. 
Table 2: Malaria indicators and morbidity by study area

\begin{tabular}{|c|c|c|c|c|c|c|}
\hline & \multicolumn{2}{|c|}{ Sampovloun } & \multicolumn{2}{|c|}{ Koh Kong } & \multicolumn{2}{|c|}{ Preah Vihear } \\
\hline & No & $(\%)$ & No & (\%) & No & $(\%)$ \\
\hline \multicolumn{7}{|l|}{ Microscopy diagnosis } \\
\hline No of examined slides & $\underline{4074}$ & & $\underline{2624}$ & & $\underline{4954}$ & \\
\hline P. spp. positive & 123 & $(3.0)$ & 184 & (7.0) & 610 & $(12.3)$ \\
\hline single infections & 115 & $(2.8)$ & 167 & $(4.1)$ & 573 & $(11.6)$ \\
\hline$P$ falciparum & 59 & (1.4) & 120 & (2.9) & 455 & $(9.2)$ \\
\hline$P$ vivax & 56 & (1.4) & 46 & (I.I) & 115 & $(2.3)$ \\
\hline$P$ malariae & 0 & $(0.0)$ & 1 & $(0.02)$ & 3 & $(0.1)$ \\
\hline mixed infections & 8 & $(0.2)$ & 17 & $(0.4)$ & 37 & $(0.7)$ \\
\hline$P$ falciparum/vivax & 8 & $(0.2)$ & 14 & $(0.3)$ & 36 & $(0.7)$ \\
\hline$P$ falciparum/malariae & 0 & $(0.0)$ & 3 & $(0.1)$ & 1 & $(0.02)$ \\
\hline \multicolumn{7}{|l|}{ Gametocyte carriage } \\
\hline P. falciparum & 6 & $(9.0)$ & 20 & $(14.6)$ & 53 & $(10.8)$ \\
\hline P. vivax & 7 & $(10.9)$ & 2 & $(3.3)$ & 0 & $(0.0)$ \\
\hline \multicolumn{7}{|l|}{ Spleen rates* } \\
\hline No of surveyed individuals & $\underline{3451}$ & & $\underline{2623}$ & & $\underline{4954}$ & \\
\hline with splenomegaly & 46 & $(1.3)$ & 23 & $(0.9)$ & 60 & $(1.2)$ \\
\hline No of children 2-9 years old & $\underline{839}$ & & $\underline{746}$ & & $\underline{1620}$ & \\
\hline with splenomegaly & 10 & $(1.2)$ & $\overline{11}$ & $(1.5)$ & 35 & $(2.2)$ \\
\hline No of $P$. spp. positive individuals & $\underline{98}$ & & $\underline{184}$ & & $\underline{610}$ & \\
\hline with splenomegaly & $\overline{9}$ & $(9.2)$ & $\overline{11}$ & $(6.0)$ & $\overline{36}$ & $(5.9)$ \\
\hline \multicolumn{7}{|l|}{ Fever rates* } \\
\hline No of surveyed individuals & 3842 & & 2623 & & 4954 & \\
\hline No of individuals with fever & $\underline{210}$ & & $\underline{415}$ & & $\underline{603}$ & \\
\hline$\overline{\text { malaria attributable fever cases } \dagger}$ & $\overline{35}$ & $(16.7)$ & $\overline{42}$ & $(10.1)$ & $\overline{199}$ & $(33.0)$ \\
\hline No of $P$. spp. positive individuals & $\underline{117}$ & & $\underline{184}$ & & $\underline{610}$ & \\
\hline symptomatic malaria cases $\dagger$ & 35 & $(29.9)$ & $\overline{42}$ & $(22.8)$ & 199 & (32.6) \\
\hline
\end{tabular}

* For some individuals, fever and splenomegaly data were not available.

$\dagger$ P. spp. positive individuals with fever

Results of microscopy diagnosis and clinical examination are shown for each surveyed area. Percentages of Plasmodium and subspecies infections are with respect to total numbers of examined slides, while rates of splenomegaly and fever are with respect to total numbers of surveyed individuals.

ciparum $(27.9 \%$ versus $45.1 \%, p<0,001)$ and $P$. vivax (20.1\% versus $63.9 \%, p<0.001)$.

\section{Spatial distribution of prevalence}

As visualized in Figure 2, villages displaying the highest malaria rates are clustered along roads or tracks penetrating into recently colonized forested areas not served by health services. Koh Kong displayed the greatest spatial heterogeneity, with village prevalence ranging from $0 \%$ in the coastal area up to $60.1 \%$ in the Cardamom mountains (Figure 2C). The highest prevalences of malaria infection were clustered in remote villages located about $60 \mathrm{~km}$ north-east of Koh Kong city, in a mountainous and forested area not covered by public heath centers. Notably, the villages most at malaria risk, with prevalence rates above $50 \%$, are located in remote places, accessible by road during the dry season only. In Preah Vihear, forests and health facilities were more uniformly distributed, and prevalence varied from $0.9 \%$ to $33.5 \%$ (Figure $2 \mathrm{~B}$ ). In the north of this province, a cluster of villages with low prevalence $(<10 \%)$ coincided with a lack of evergreen forest in the surrounding areas. In the south, numerous villages with high prevalence have settled along the main road leading to the Thai border, which apparently constitutes a route along which malaria parasites do circulate and spread over the entire province. The narrowest difference was observed in Sampovloun, with uniformly low prevalence $(\leq 8.5 \%)$, except in one village $(17.7 \%)$ which actually corresponds to a forest camp ("chamkar"). The distance to the nearest health facility never exceeded 10 
$\mathrm{km}$, and the median distance to evergreen forest was the greatest of the three areas (Figure 2A). An effect of the distance from the villages to forests and to health facilities was observed in the three areas. The prevalence rate increased concomitantly with the distance to health center whereas an inverse relation was observed with the distance to forest fringe (Figure 2D).

\section{Risk factors}

Gender, age, bednet use and occupation significantly influenced the risk of Plasmodium spp. infections, depending on the survey area (Table 1). The factor "occupation" was excluded from further analyses because of its strong co-linearity with age in all areas $\left(\mathrm{R}^{2}=0.68-0.73\right)$. Multivariate regression combining all individual risk factors covariates confirmed the significant effect of the distanceto-forest and distance-to-health-facility (Table 3). Males had an increased risk of Plasmodium spp. infection in the three areas, the highest risk $(\mathrm{OR}=2.306)$ being observed in Sampovloun. The age group at highest risk of malaria differed in each area, being 15-39 years in Sampovloun, 5-39 years in Koh Kong, and 0-39 years in Preah Vihear. In Sampovloun, we found a significantly increased risk for males aged 15-39 years, due to an interaction between age and gender. A protective effect of bednets was detected in Preah Vihear. Due to the large coverage and regular use of bednets by population in other provinces, such an effect was not detected in Koh Kong and Sampovloum by the multivariate analysis, though it was readily established by the univariate analysis in Sampovloun (Table 1). An increased distance to forest tended to reduce the infection risk in Preah Vihear and in Koh Kong, whereas an increased distance to health facilities tended to increase the risk of malaria infection.

\section{Risk factors and relative importance of $P$. falciparum and P. vivax}

There was no major difference between the risk factors for $P$. falciparum and $P$. vivax infections (Table 3 ). In particular, the association of distance-to-forest and distance-tohealth-facility with malaria infection was identical for both species. Individuals aged 15-39 years tended to be at similar risk in all regions and for both species. However, the risk of $P$. vivax in Koh Kong and Preah Vihear was higher for children aged $<15$ years and was not associated with gender. In Sampovloun, $P$. vivax infections were more frequent and accounted for more Plasmodium spp. infections in $<15$ years old children than in individuals $\geq$ 15 years old $(73.3 \%$ versus $45.2 \%, p=0.007)$. We also observed a higher proportion of $P$. vivax cases in some villages with low malaria prevalence $(<5 \%)$ than in the others $(53.7 \%$ versus $26.4 \%, p<0,001)$.

\section{Discussion}

Accurate information on incidence and prevalence is invaluable for planning control activities and monitoring their efficacy over time. It is also an indicator of effectiveness of the methods used for evaluating the impact of malaria on public health and economy $[20,21]$. Models based on epidemiological and demographic data predict that the actual malaria incidence level is broadly underestimated by routine HIS due to the uneven coverage of the public health facilities and the number of recorded cases treated by the private health sector.

In this study, the first large population-based survey was conducted to provide baseline parasitologic information for populations living in western Cambodia, and to assess the extent to which the malaria situation depicted by the Cambodian HIS is consistent with data collected using an active case detection approach. Unsurprisingly, a much higher prevalence than reported by the national HIS was observed. The discrepancy of the fever-associated Plasmodium infections with the time and space-adjusted clinical malaria cases recorded by the HIS showed large geographical variation. Estimated factors of discrepancy between passive and active case detection ranged from 5-fold in Sampovloun to more than 100-fold in Koh Kong. As translation of malaria point prevalence to incidence is not straightforward, these values are only indicative of the size and magnitude of under-reporting through routine HIS. Obviously, this system does not catch a significant proportion of cases and, as a result, downplays certain priorities for malaria control. For example, the low reported annual incidence of malaria cases in Koh Kong per year (API $=5.5$ per 1,000 individuals) contrasts with the high prevalence of symptomatic malaria carriers detected in the study population (16 cases per 1,000 individuals during the survey, see Table 2). Better estimates are captured by the HIS at Sampovloun and Preah Vihear with API of 36.4 and 39.2, respectively, as compared to 8.6 and 40 clinical cases per 1,000 detected during the survey in these areas. These findings are likely to reflect the unequal distribution of public health facilities across the country [22] and the strong competition of the private health sector in Cambodia $[12,13]$. This cross-sectional survey provides a point prevalence of malaria in three provinces bordering Thailand. Additional studies need to be done at different time points during the year and in other areas of Cambodia to better define the major points of divergence with current perception of the malaria situation via HIS.

The risk factor analysis provided a better understanding of local risk and malaria transmission patterns. Obviously, the distance to forest fringe and health facilities have a major impact on malaria transmission in Cambodia. Unsuspected foci, such as the hyperendemic villages in the remote Cardamom mountains of Koh Kong, should 


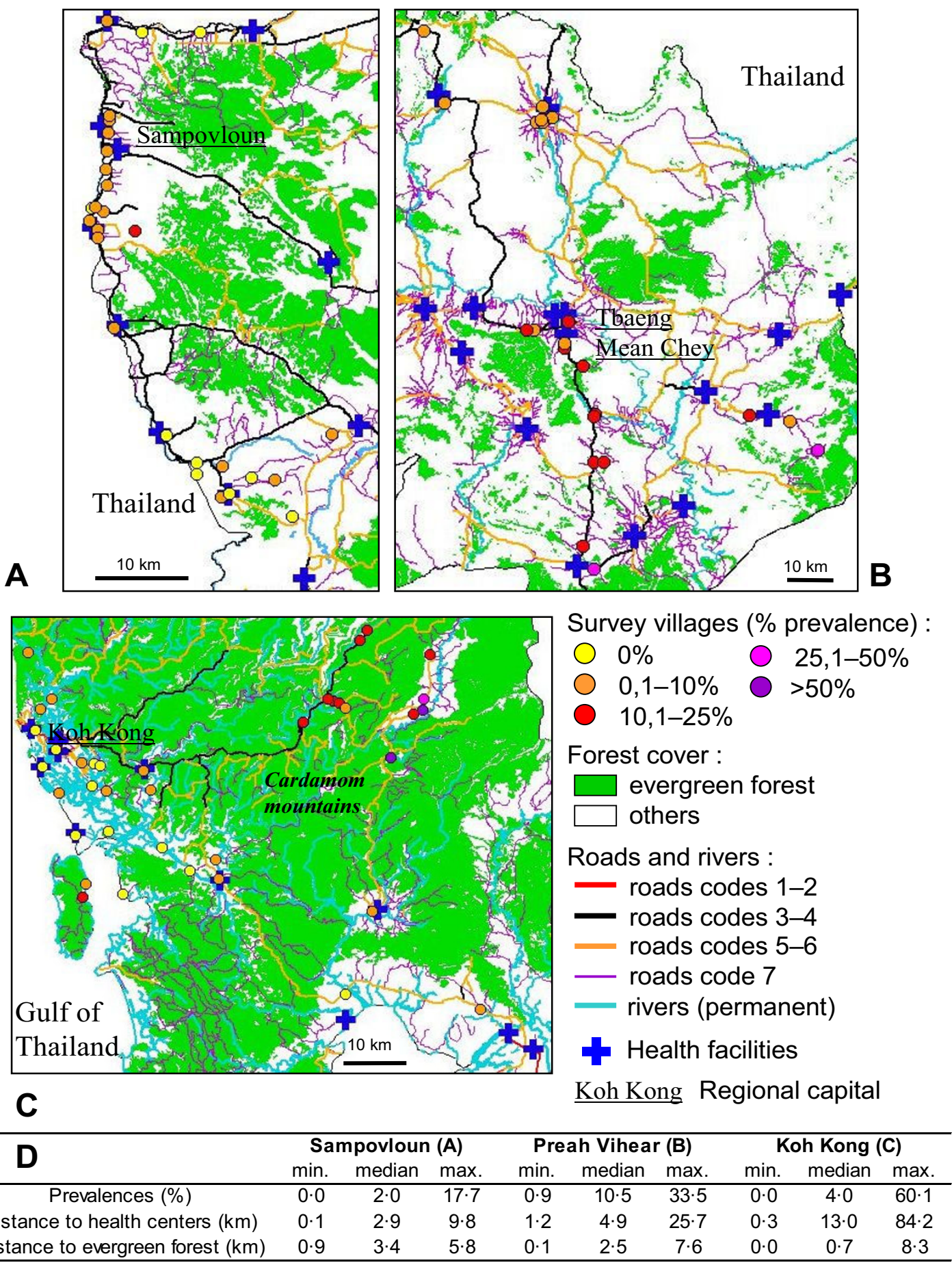

Figure 2

Maps of the study areas Sampovloun (A), Preah Vihear (B) and Koh Kong (C). Maps 2A, B and C show the distribution of microscopy-based age/gender-standardized malaria prevalence in the surveyed villages, evergreen forest, roads according to their quality (codes I-2: hard surface roads passable in all weather, codes 3-4: loose surface roads passable in all weather, codes 5-6: cart tracks and loose surface roads passable in dry weather only, code 7: footpaths), rivers, and positions of public health facilities. Figure 2D shows the median, minimum and maximum values of village-based age/gender-standardized Plasmodium prevalence, distances to public health facilities and distances to evergreen forest. 
Table 3: Multivariate analysis of risk factors

\begin{tabular}{|c|c|c|c|c|c|c|c|c|c|}
\hline \multirow{2}{*}{$\begin{array}{l}\text { Plasmodium spp. } \\
\text { Variables at individual level : (tested/reference) }\end{array}$} & \multicolumn{3}{|c|}{ Sampovloun* } & \multicolumn{3}{|c|}{ Koh Kong } & \multicolumn{3}{|c|}{ Preah Vihear } \\
\hline & & & & & & & & & \\
\hline & OR & $95 \% \mathrm{Cl}$ & $\mathbf{p}$ & OR & $95 \% \mathrm{Cl}$ & $\mathbf{p}$ & OR & $95 \% \mathrm{Cl}$ & $p$ \\
\hline gender (male/female) & 2.31 & $|.56-3.4|$ & $<0.001$ & 1.69 & $1.19-2.38$ & 0.003 & 1.31 & I.10-I.57 & 0.003 \\
\hline age $(0-5$ years $/ \geq 40$ years $)$ & 0.4 & $0.13-1.23$ & 0.109 & 1.53 & $0.59-3.95$ & 0.377 & $1.4 \mathrm{I}$ & $0.96-2.07$ & 0.084 \\
\hline age $(5-14$ years $/>40$ years $)$ & 0.6 & $0.32-1.14$ & 0.118 & 3.46 & $1.96-6.11$ & $<0.001$ & 1.85 & $1.30-2.65$ & 0.001 \\
\hline age ( $\mid 5-39$ years $/>40$ years) & 1.97 & $1 .|4-3.4|$ & 0.016 & 2.68 & $1.53-4.67$ & 0.001 & 1.63 & $1.14-2.33$ & 0.008 \\
\hline bednet (used/not used) & 0.65 & $0.26-1.65$ & 0.364 & 1.79 & $0.54-5.95$ & 0.341 & 0.6 & $0.46-0.77$ & $<0.001$ \\
\hline \multicolumn{10}{|l|}{ Variables at village level : (increasing distances) } \\
\hline & OR & $95 \% \mathrm{Cl}$ & $p$ & OR & $95 \% \mathrm{Cl}$ & $\mathbf{p}$ & OR & $95 \% \mathrm{Cl}$ & $p$ \\
\hline distance to forest & 1.21 & $0.85-1.74$ & 0.146 & 0.8 & $0.59-1.07$ & 0.065 & 0.82 & $0.72-0.94$ & 0.003 \\
\hline distance to health center & 0.86 & $0.70-1.07$ & 0.085 & 1.05 & $1.04-1.07$ & $<0.001$ & 1.03 & $0.99-1.08$ & 0.076 \\
\hline \multicolumn{10}{|c|}{$\begin{array}{l}* \text { Sex-age interaction was observed upon analysis with two ageclasses (tested/reference : age } \geq 15 \text { years } /<15 \text { years) sex } \times \text { age: } O R=4.37,95 \% C l=I .82-10.47, P=0.00 I, \text { likelihood-ratio test } A: L R=11.08, p< \\
0.00 I\end{array}$} \\
\hline Plasmodium falciparum & & Sampovlo & & & Koh Kol & & & Preah Vih & \\
\hline \multicolumn{10}{|l|}{ Variables at individual level : (tested/reference) } \\
\hline & OR & $95 \% \mathrm{Cl}$ & $p$ & OR & $95 \% \mathrm{Cl}$ & $p$ & OR & $95 \% \mathrm{Cl}$ & $p$ \\
\hline gender (male/female) & 2.75 & $1.6 I-4.73$ & $<0.001$ & 1.67 & $1.13-2.46$ & 0.01 & 1.43 & $1.17-1.75$ & $<0.001$ \\
\hline age $(0-5$ years $/>40$ years $)$ & 0.3 & $0.07-1.40$ & 0.127 & 1.03 & $0.32-3.31$ & 0.965 & 1.19 & $0.78-1.82$ & 0.425 \\
\hline age (5-14 years/> 40 years) & 0.3 & $0.12-0.75$ & 0.01 & 2.86 & $1.52-5.38$ & 0.001 & 1.7 & $|| 6-2.5 \mid$. & 0.007 \\
\hline age ( $15-39$ years/> 40 years) & 1.77 & $0.89-3.50$ & 0.101 & 2.51 & $1.36-4.64$ & 0.003 & 1.48 & $1.00-2.18$ & 0.049 \\
\hline bednet (used/not used) & 0.37 & $0.13-1.05$ & 0.06 & 1.79 & $0.47-6.76$ & 0.393 & 0.56 & $0.42-0.73$ & $<0.001$ \\
\hline \multicolumn{10}{|l|}{ Variables at village level : (increasing distances) } \\
\hline & OR & $95 \% \mathrm{Cl}$ & $p$ & OR & $95 \% \mathrm{Cl}$ & $\mathbf{p}$ & OR & $95 \% \mathrm{Cl}$ & $\mathbf{p}$ \\
\hline distance to forest & 1.2 & $0.80-1.81$ & 0.191 & 0.85 & $0.63-1.15$ & 0.15 & 0.82 & $0.68-0.99$ & 0.018 \\
\hline distance to health center & 0.87 & $0.69-1.10$ & 0.121 & 1.05 & $1.03-1.06$ & $<0.001$ & 1.05 & $0.99-1.12$ & 0.049 \\
\hline Plasmodium vivax & & Sampovlo & & & Koh Kol & & & Preah Vih & \\
\hline \multicolumn{10}{|l|}{ Variables at individual level : (tested/reference) } \\
\hline & OR & $95 \% \mathrm{Cl}$ & $\mathbf{p}$ & OR & $95 \% \mathrm{Cl}$ & $\mathbf{p}$ & OR & $95 \% \mathrm{Cl}$ & $\mathbf{p}$ \\
\hline gender (male/female) & 1.94 & $1.15-3.28$ & 0.013 & 1.29 & $0.75-2.21$ & 0.357 & 1.06 & $0.76-1.48$ & 0.725 \\
\hline age $(0-5$ years $/>40$ years $)$ & 0.91 & $0.22-3.74$ & 0.899 & 2.13 & $0.49-9.27$ & 0.312 & 2.84 & $1.24-6.49$ & 0.014 \\
\hline age $(5-14$ years $/>40$ years $)$ & 1.36 & $0.53-3.46$ & 0.521 & 3.8 & $1.42-10.14$ & 0.008 & 2.77 & $1.26-6.13$ & 0.012 \\
\hline age ( $15-39$ years $/>40$ years) & 2.58 & $1.07-6.21$ & 0.035 & 2.38 & $0.89-6.41$ & 0.086 & 2.17 & $0.97-4.82$ & 0.058 \\
\hline bednet (used/not used) & 2.42 & $0.32-18.51$ & 0.394 & 1.92 & $0.25-15.08$ & 0.534 & 0.77 & $0.47-1.25$ & 0.284 \\
\hline \multicolumn{10}{|l|}{ Variables at village level : (increasing distances) } \\
\hline & OR & $95 \% \mathrm{Cl}$ & $\mathbf{p}$ & OR & $95 \% \mathrm{Cl}$ & $\mathbf{p}$ & OR & $95 \% \mathrm{Cl}$ & $\mathbf{p}$ \\
\hline distance to forest & 1.16 & $0.81-1.66$ & 0.212 & 0.84 & $0.64-1.10$ & 0.103 & 0.88 & $0.79-0.97$ & 0.005 \\
\hline distance to health center & 0.95 & $0.77-1.17$ & 0.299 & 1.04 & $1.03-1.05$ & $<0.001$ & 1.00 & $0.97-1.03$ & 0.435 \\
\hline
\end{tabular}

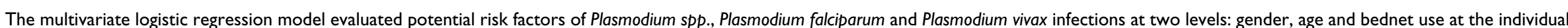
level (interview of surveyed individuals), distances to evergreen forest and to public health centers at the village level (spatial analysis). For the individual level, odds ratios (OR), 95\% confidence intervals

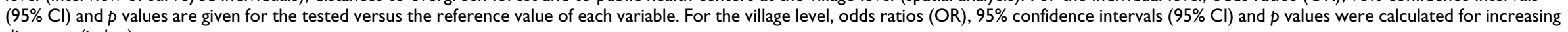
distances (in $\mathrm{km}$ ). 
be taken into account in future control activities, especially with regards of the marked prevalence of multidrug resistant malaria in these regions $[5,14,15]$. The increased infection risk associated with increased distance from health facilities points to the need to improve access to health care, especially in remote areas. Village malaria workers (VMW) or outreach activities in such areas can help until the infrastructures improve and population stabilizes. In Koh Kong, and particularly in Preah Vihear, the higher infection risk for children, and the effect of distance to forest and bednet use, are consistent with transmission occurring in forest-fringe villages. Therefore, personal control measures such as impregnated bed-net use should be promoted or reinforced in these villages. In Sampovloun, risk of infection was highest for individuals aged 15-39 years mostly involved in farming and forest activities outside the village, suggesting that infection with malaria parasites occurs frequently in remote forest camps or new settlements and not in long-established villages. Thus, the distribution of impregnated hammock nets and information of forest workers on preventative behavior should be strengthened in this area. Two reasons account for the under-representation of adult men in our study population: i) individuals working outside their villages for farming and forest activities were not present the day of the survey; ii) this age group is poorly represented in Cambodian population which is characterised by a specific deficit of males among the adult population because of excess mortality from civil war [23]. Beside this limitation, this group was at higher risk of malaria in all survey areas, with an age-gender interaction being detected in Sampovloun. In the 15-39 year age group, males are likely to be more exposed to local malaria vectors due to farming or forest activities (woodcutting, hunting, gemstone mining), working with the upper body uncovered and staying outside late at night with no bednet protection $[4,24,25]$. These observations are consistent with previous studies on forest malaria and malaria risk for men in South-East Asia [24-27]. The spatial distribution of prevalence and the identification of the villages at malaria risk point to a stratified malaria endemicity in Cambodia. Considering the patchy situation of malaria in this country, control strategies should therefore be primarily designed for and adjusted to the village level.

For the first time the rate of fever-associated malaria infections was documented at the community level. A low proportion of fever cases was attributable to malaria, confirming that fever is a poor indicator for presumptive treatment of malaria, even in hypoendemic areas [28]. A large overlooked reservoir of asymptomatic malaria infections was identified in all three regions. This is particularly obvious in Sampovloum area were transmission is low. The conclusion is that the existence of such reservoir of malaria parasites should be considered in the future fol- low-up of control measures. Longitudinal studies are needed to assess the variation of asymptomatic parasite carriage over time, and its exact contribution to transmission. A complementary approach to continuous monitoring of clinical case at health facilities would be to perform population-based prevalence studies on a regular basis, possibly every second or third year. In this respect, a systematic survey of areas and populations at highest risk such as new settlements, remote rural and forested areas, adult male forest transmigrants, is the priority.

P. vivax was responsible for more infections than reported by the HIS [3], accounting for half of malaria cases in Sampovloun. The treatment seeking behavior of Cambodian patients may explain the underestimation of $P$. vivax infections by the HIS [12,13]. P. vivax infections do not lead to complications as $P$. falciparum and are usually treated by chloroquine which is readily available in the private health sector. A higher frequency or risk of $P$. vivax infections was observed in children, in contrast to the higher $P$. falciparum infection risk in groups involved in forest activities. The proportion of $P$. vivax infections was also higher in villages with low malaria prevalence and better access to health care facilities, whereas $P$. falciparum dominated in high-risk areas. This may be due to an easy access and use of anti-malarial drugs in villages, especially for children. Indeed, adequate treatment is expected to clear radically $P$. falciparum, whereas $P$. vivax parasites persist as hypnozoites that may relapse. The elimination of $P$. falciparum may even promote reappearance of cryptic $P$. vivax in mixed infections [29-31]. Whether the extensive use of artesunate plus mefloquine combination since 2000 has contributed for the changes observed in the falciparum to vivax ratio is still uncertain. Interestingly, Ratcliff and Colleagues recently showed higher parasitological failure with $P$. vivax after artemether-lumefantrine than after dihydroartemisinin-piperaquine treatment, as results of the shorter half life of lumefrantrine compared to piperaquine [32]. The mefloquine pharmacokinetic being similar to that of piperaquine, an increasing prevalence of $P$. vivax infections under artesunate plus mefloquine in western Cambodia might therefore indicate a reduced susceptibility of $P$. vivax in this area. This question definitely needs to be further explored. An alternative, but not exclusive explanation, could be higher $P$. falciparum transmission in forests and higher $P$. vivax transmission inside villages. Indeed, malaria and particularly $P$. vivax transmission by minor vectors has been reported in neighbouring countries in villages surrounded by rice fields $[33,34]$. Compilation of province-based HIS data from 1999 to 2002 indicated that $P$. vivax incidence increased in the north-western Battambang and Pailin provinces despite a decreasing $P$. falciparum incidence. This contrasts with the marked decrease of $P$. falciparum and moderate decrease of $P$. vivax in the rest of the coun- 
try. A change from dominant $P$. falciparum to dominant $P$. vivax was observed in 1996 on the Thai side of this particular area $[11,30,35]$. Whether the resurgence of $P$. vivax infections in some areas is linked to specific vectors or topography affecting the distribution of mosquito breeding habitats is not clear and requires further investigation.

In conclusion, this study confirms that the current CNM control strategies such as the distribution of impregnated bednets and the setting-up of VMW in forest-fringe villages are useful, efficient and should be extended [3,4]. At the same time, it raises new questions and recommendations. Data on prevalence and risk factors point to an inadequate description of distribution of species and disease risk in Cambodia, and highlight the need for deployment of additional facilities in under covered areas. Means to capture the cases treated by the private sector should be strengthened [4]. The identification of geographical risk factors will help the mapping of malaria risks, but information on forest coverage should be regularly updated and currently unregistered private health facilities included in the analysis. This, together with ongoing efforts by the CNM to assess the malaria situation better [36], should help reducing the malaria burden in all risk areas of Cambodia

\section{Authors' contributions}

TF and OMP designed the study and were responsible for its coordination. SD and LC were responsible for coordination of the field surveys and the microscopy analysis. SI, LC and PL supervised the surveys and data collection in the field. SN, RS and NK participated in the surveys, the data collection and entry in the database. SI and SV verified and analyzed the data. SI drafted the manuscript, with the help of OMP and TF. All other authors contributed to the data interpretation and critically reviewed the manuscript.

\section{Acknowledgements}

We are grateful to all study participants and provincial health staff of the Ministry of Health for their kind contribution to the study. We also thank the field and laboratory teams of the National Centre for Parasitology, Entomology and Malaria Control (CNM) for conducting field surveys and microscopy diagnosis, respectively. Thanks to $\mathrm{Dr}$. T. Sochantha from the Entomology Department, CNM, for providing information on malaria vectors, and Dr. T. Bunkea from the Epidemiology Department, CNM, for providing HIS data. We would like to acknowledge Dr. P. Glaziou, former head of the Epidemiology and Public Health Laboratory, Pasteur Institute of Cambodia, as well as Loïc Chartier and Edith Langevin from the Epidemiology of Emerging Diseases Unit at the Pasteur Institute of Paris, for conducting preliminary statistical analyses. Thanks to $\mathrm{V}$. Obsomer from the Institute of Tropical Medicine, Antwerp, Belgium, for helpful support in creating ArcView maps and conducting spatial analyses. Many thanks to F. Ariey for helpful discussions, advice and continuous support, as well as to Drs $C$. Rogier and A. Fontanet for their critical reading of the manuscript. We are grateful to Dr Reiko Tsuyuoka, (WHO Representative Office, Phnom Penh, Cambodia) for her help and constant support.

\section{Funding source}

This work was funded by the French Ministry of Research and New Technologies. S. Incardona was supported by a 'Fondation Jeunesse Internationale' Fellowship of the 'Fondation de France'. The funding source was not involved in study design; in the collection, analysis, and interpretation of data; in the writing of the report; and in the decision to submit the paper for publication.

\section{References}

I. Olumese $\mathrm{P}$ : Changing the global picture of malaria - myth or reality? MIM 4th Pan-African Malaria Meeting, Yaoundé, Cameroun, 13 18 nov 2005

2. World Health Organization, Regional Office for the Western Pacific: Malaria epidemiology, Cambodia [http:// www.wpro.who.int/sites/mvp/epidemiology/malaria/]

3. Annual Progress Reports 1999-2005. National Centre for Parasitology, Entomology and Malaria Control, Ministry of Health of Cambodia, Phnom Penh, Cambodia .

4. Chatterjee P: Cambodia's fight against malaria. Lancet 2005, 366:191-192.

5. Socheat $D$, Denis MB, Fandeur $T$, Zhang Z, Yang $H, X u$ J, Zhou $X$, Phompida S, Phetsouvanh R, Lwin S, Lin K, Win T, Than SW, Htut Y, Prajakwong S, Rojanawatsirivet C, Tipmontree R, Vijaykadga S, Konchom S, Cong le D, Thien NT, Thuan le K, Ringwald P, Schapira A, Christophel E, Palmer K, Arbani PR, Prasittisuk C, Rastogi R, Monti F, Urbani C, Tsuyuoka R, Hoyer S, Otega L, Thimasarn K, Songcharoen S, Meert JP, Gay F, Crissman L, Cho-Min-Naing , Chansuda W, Darasri D, Indaratna K, Singhasivanon P, Chuprapawan S, Looareesuwan S, Supavej S, Kidson C, Baimai V, Yimsamran S, Buchachart K: Mekong malaria. II. Update of malaria, multi-drug resistance and economic development in the Mekong region of Southeast Asia. Southeast Asian J Trop Med Public Health 2003, 34(Suppl 4): $1-102$.

6. World Health Organization, Western Pacific Region Health databank, 2005 revision, Cambodia [http://www.wpro.who.int/ countries $/ 05 \mathrm{cam} /]$

7. Denis MB, Meek SR: Malaria in Cambodia. Southeast Asian J Trop Med Public Health 1992, 23(Suppl 4):23-28.

8. Delbove P, Capponi M: Groupes ethniques et répartition des hématozoaires en Indochine méridionale. Bull Soc Pathol Exot 1948, 41:361-364.

9. Eyles DE, Wharton RH, Cheong WH, Warren M: Studies on Malaria and Anopheles balabacensis in Cambodia. Bull World Health Organ 1964, 30:7-21.

10. Guerrero IC, Chin W, Collins WE: A survey of malaria in Indochinese refugees arriving in the United States, 1980. Am J Trop Med Hyg 1982, 31:897-901.

II. Kitvatanachai S, Janyapoon K, Rhongbutsri P, Thap LC: A survey on malaria in mobile Cambodians in Aranyaprathet, Sa Kaeo Province, Thailand. Southeast Asian J Trop Med Public Health 2003, 34:48-53.

12. Demographic and Health Survey, 2000. National Institute of Statistics, Ministry of Planning and Ministry of Health, Phnom Penh, Cambodia .

13. Socheat D, Boukheng T, Duzey O, Kim S, Ros S, Rose G, Staley R, Tsuyuoka R, S Y: Community drug use practices in malaria in Cambodia : a cross-sectional study, February 2003. National Center for Parasitology, Entomology and Malaria Control, Phnom Penh, Cambodia

14. Khim N, Bouchier C, Ekala MT, Incardona S, Lim P, Legrand E, Jambou $\mathrm{R}$, Doung $\mathrm{S}$, Puijalon OM, Fandeur T: Countrywide survey shows very high prevalence of Plasmodium falciparum multilocus resistance genotypes in Cambodia. Antimicrob Agents Chemother 2005, 49:3।47-3I52.

15. Lim P, Chim P, Sem R, Nemh S, Poravuth Y, Lim C, Seila S, Tsuyuoka $R$, Denis MB, Socheat D: In vitro monitoring of Plasmodium falciparum susceptibility to artesunate, mefloquine, quinine and chloroquine in Cambodia: 200I-2002. Acta Trop 2005, 93:3I-40.

16. Manguin S, Mouchet J, Coosemans M: Molecular identification of sibling Anopheles species: example of the Anopheles minimus and Anopheles dirus complexes, major malarial vectors in Southeast Asia. Med Trop (Mars) 2001, 61:463-469. 
17. Trung HD, Van Bortel W, Sochantha T, Keokenchanh K, Quang NT, Cong LD, Coosemans M: Malaria transmission and major malaria vectors in different geographical areas of Southeast Asia. Trop Med Int Health 2004, 9:230-237.

18. [http://sampsize.sourceforge.net/iface/index.html].

19. Boisier P, Jambou R, Raharimalala L, Roux J: Relationship between parasite density and fever risk in a community exposed to a low level of malaria transmission in Madagascar highlands. Am J Trop Med Hyg 2002, 67:137-I 40.

20. Carter R, Mendis K: Measuring malaria. Am J Trop Med Hyg 2006, 74:187-188.

21. Snow RW, Guerra CA, Noor AM, Myint HY, Hay SI: The global distribution of clinical episodes of Plasmodium falciparum malaria. Nature 2005, 434:2 I4-217.

22. Joint Health Sector Review Report, may 200I. Ministry of Health of the Kingdom of Cambodia. Phnom Penh, Cambodia .

23. Census 1990 of the National Institute of Statistics, Ministry of Planning, Phnom Penh, Cambodia [http://www.nis.gov.kh/ CENSUSES/Census 1998/index.htm]

24. Erhart A, Ngo DT, Phan VK, Ta TT, Van Overmeir C, Speybroeck N, Obsomer V, Le XH, Le KT, Coosemans M, D'Alessandro U: Epidemiology of forest malaria in central Vietnam: a large scale cross-sectional survey. Malar J 2005, 4:58.

25. Erhart A, Thang ND, Hung NQ, Toi le V, Hung le $X$, Tuy TQ, Cong le D, Speybroeck N, Coosemans M, D'Alessandro U: Forest malaria in Vietnam: a challenge for control. Am J Trop Med Hyg 2004, 70: 1 10-118.

26. Somboon P, Aramrattana A, Lines J, Webber R: Entomological and epidemiological investigations of malaria transmission in relation to population movements in forest areas of northwest Thailand. Southeast Asian J Trop Med Public Health 1998, 29:3-9.

27. Vythilingam I, Sidavong B, Chan ST, Phonemixay T, Vanisaveth V, Sisoulad P, Phetsouvanh R, Hakim SL, Phompida S: Epidemiology of malaria in Attapeu Province, Lao PDR in relation to entomological parameters. Trans $R$ Soc Trop Med Hyg 2005, 99:833-839.

28. Luxemburger C, Nosten F, Kyle DE, Kiricharoen L, Chongsuphajaisiddhi T, White NJ: Clinical features cannot predict a diagnosis of malaria or differentiate the infecting species in children living in an area of low transmission. Trans $R$ Soc Trop Med Hyg 1998, 92:45-49.

29. Mayxay M, Pukrittayakamee S, Newton PN, White NJ: Mixed-species malaria infections in humans. Trends Parasitol 2004, 20:233-240.

30. Sattabongkot J, Tsuboi T, Zollner GE, Sirichaisinthop J, Cui L: Plasmodium vivax transmission: chances for control? Trends Parasitol 2004, 20: 192-198.

31. Snounou G, White NJ: The co-existence of Plasmodium : sidelights from falciparum and vivax malaria in Thailand. Trends Parasitol 2004, 20:333-339.

32. Ratcliff A, Siswantoro H, Kenangalem E, Wuwung RM, Laihad F, Ebsworth EP, Anstey NM, Tiitra E, Price RN: Two fixed-dose artemisinin combinations for drug-resistant falciparum and vivax malaria in Papua, Indonesia: an open-label randomised comparison. The Lancet 2007, 369:757-765.

33. Apiwathnasor C, Prommongkol S, Samung Y, Limrat D, Rojruthai B: Potential for Anopheles campestris (Diptera: Culicidae) to transmit malaria parasites in $\mathbf{P a}$ Rai subdistrict (Aranyaprathet, Sa Kaeo Province), Thailand. J Med Entomol 2002, 39:583-586.

34. Kobayashi J, Somboon $P$, Keomanila H, Inthavongsa S, Nambanya S, Inthakone S, Sato Y, Miyagi I: Malaria prevalence and a brief entomological survey in a village surrounded by rice fields in Khammouan province, Lao PDR. Trop Med Int Health 2000, 5:17-2I.

35. Konchom S, Singhasivanon P, Kaewkungwal J, Chupraphawan S, Thimasarn K, Kidson C, Rojanawatsirivet C, Yimsamran S, Looareesuwan S: Trend of malaria incidence in highly endemic provinces along the Thai borders, I99 I-200I. Southeast Asian J Trop Med Public Health 2003, 34:486-494.

36. Malaria baseline survey 2004. National Centre of Parasitology, Entomology and Malaria Control, Ministry of Health of Cambodia, Phnom Penh, Cambodia .
Publish with Biomed Central and every scientist can read your work free of charge

"BioMed Central will be the most significant development for disseminating the results of biomedical research in our lifetime. "

Sir Paul Nurse, Cancer Research UK

Your research papers will be:

- available free of charge to the entire biomedical community

- peer reviewed and published immediately upon acceptance

- cited in PubMed and archived on PubMed Central

- yours - you keep the copyright

Submit your manuscript here:

http://www.biomedcentral.com/info/publishing_adv.asp
BiolMedcentral 